Original Article

\title{
Cross-Sectional Analysis of Incidence and Extent of H.Pylori Infestation among Symptomatic Population of Shaheed Benazirabad
} Aatir H. Rajput ${ }^{1,2} \& 3$, Maleeha Saleh Unar ${ }^{1 \& 2} \&$ Muhammad Muneeb $^{1 \& 2}$

\author{
1. LUMHS Research Forum
}

2. Liaquat University Hospital, Hyderabad

3. Liaquat University of Medical \& Health Sciences, Jamshoro

Corresponding Author: aatirh.rajput@gmail.com

\section{Abstract}

Background H. Pylori or Helicobacter pylori is a bacterium of gram negative origin, found in the stomach and has been attributed to peptic ulcers, chronic gastritis, and cancer of the stomach (ailments that formerly were not thought to occur due to microbes) ever since it was identified nearly three decades ago. Objective: Nearly half of the global population harbors $\mathrm{H}$. pylori in its upper gastrointestinal tract. However, a major proportion (i.e. eighty percent) of the victims remain asymptomatic. This research aims to determine the incidence and extent of Helicobacter Pylori infestation among symptomatic population of Shaheed Benazirabad and provide the basis for future studies investigating the extent of infestation and its relationship with symptoms. Methodology This cross-sectional analysis of incidence and extent of H. Pylori infestation was done on the basis of ELISA test results from a mainstream laboratory (Arif Diagnostics) the only laboratory, equipped with the technology to carry out this test. The data of 100 symptomatic patients visiting the laboratory in the month of June, 2014 was collected and test result was analyzed on SPSS v.16.0. Results The Mean H. Pylori levels were higher in females (12.54ug/dl) than in males $(8.61 \mathrm{ug} / \mathrm{dl})$. The maximum level of infestation reported in symptomatic females $(58.63 \mathrm{ug} / \mathrm{dl})$ was also considerably higher than that of symptomatic males $(27.54 \mathrm{ug} / \mathrm{dl})$. H. Pylori infestation was most common (37\%) among individuals aged between eighteen to twenty-eight years. Individuals aged between twenty-nine to thirty-nine years immediately followed and $30 \%$ of the symptomatic patients fell within this age bracket, majority of the sufferers were males as compared to females. Conclusion On the basis of our result, we conclude that males are more prone to suffer from symptoms even at lower levels of infestation than females and the incidence and extent of peptic ulcer infestation decreased with decreasing age in our sample.

\section{Keywords}

Helicobacter Pylori, H. Pylori Symptomatic Population, H. Pylori Infestation, Peptic Ulcer, Campylobacter

\section{Introduction}

The pathogenesis and etiology of inflammatory diseases of gastro-duodenal origin was not fully understood, however, a little more than three decades ago a gramnegative bacterium was identified by
Warren and Marshal immediately after the occurrence of peptic ulcers, chronic gastritis and cancer of the stomach (ailments that formerly were not thought to occur due to microbes). Since then, there has been a hike of interest in a microbiologic approach to 
the pathogenesis of all sorts of inflammatory gastro-duodenal diseases. This organism was named as campylobacter pyloridis, which was then changed to campylobacter pylori and now again renamed as Helicobacter pylori (H. pylori) as a new genus because there are a number of significant differences in morphologic, structural, biochemical and genomic features.

More than fifty percent of the global population harbors $H$. pylori in its upper gastrointestinal tract. However, a major proportion (i.e. eighty-five percent) of victims is asymptomatic (Bytzer, et al, 2011). This study aimed to determine the incidence and extent of $\mathrm{H}$. Pylori infestation among symptomatic patients of duodenal and gastric ulcers, inflammatory diseases and gastric cancer in an attempt to provide the basis for future studies investigating the extent of infestation that gives rise to the similar symptoms. Furthermore, H. pylori infection was never adequately investigated in the developing and third world countries where a high prevalence rate of the bacterium is predicted. This study is situated in a poorly developed district of Sindh to benefit from the predicted high levels of this bacterium.

Acute H. pylori infection may manifest as a short-term gastritis with marked pain in the abdomen and nausea (Butcher, et al, 2003). When it turns into long-term gastritis, the symptoms (if present) mimic nonulcer dyspepsia such as pain in the stomach, bloating, nausea, belching and in severe cases vomiting or black stool may appear too (Butcher, et al, 2003; Ryan, et al, 2010). Victims of $\mathrm{H}$. pylori infection have a ten to twenty percent risk that they will develop peptic ulcers in their lifetime and a one to twenty percent chance of acquiring cancer of the stomach (Kusters, et al, 2006). Pyloric antrum inflammation is more likely to lead to ulcers in the duodenum, while corpus inflammation is more likely to lead to ulcers and cancer in the stomach (Suerbaum, et al, 2002).

In addition to that, $\mathrm{H}$. pylori has a possible part to play in the 1st stage of the process leading to common long-term inflammation, but no significant evidence exists to substantiate claims of its role in advanced stages causing cancer (Brown, 2000). Back in 2009, a meta-analysis hinted that gastric cancer risk is reduced after the elimination of $\mathrm{H}$. pylori in formerly infected patients (Fuccio, et al, 2009). Research also associates helicobacter pylori polyps and cancers in the colorectal region $(\mathrm{Wu}$, et al, 2013).

\section{Methodology}

A month long, cross-sectional analysis of incidence and extent of $\mathrm{H}$. Pylori infestation was done on 100 consecutive symptomatic patients presenting to a mainstream pathology laboratory and a sole advanced diagnostic center (Arif Diagnostics) in Shaheed Benazirabad during June 2014. The patients visiting the laboratory were referred by various doctors after they had verified that their symptoms were indicative of $\mathrm{H}$. pylori infection. The patients underwent an ELISA test and consented to share their test reports and the data therein.

In this case the final pathology reports the test results indicated the presence and extent of infestation of $\mathrm{H}$. pylori among the patients. The data collected from 100 test reports was analyzed in Ms. Excel and SPSS v.16.0 after taking written informed consent. The sample consisted of both males and females and no gender or age discrimination was done while taking data. The symptoms 
of individuals were attributed to $\mathrm{H}$. pylori infestation only if the levels were found to be greater than $5 \mathrm{ug} / \mathrm{dl}$.

\section{Results}

The decision to acquire data from patients referred by various doctors, after they had verified that their symptoms were indicative of H. pylori infection, proved fruitful. As evident in Figure 1, a large proportion of the patients reported high level of infestation $(56 \%)$ while fewer symptomatic individual $(44 \%)$ were diagnosed with lesser than normal $H$. pylori levels. Hence, their symptoms were due to causes other than $\mathrm{H}$. pylori infection.

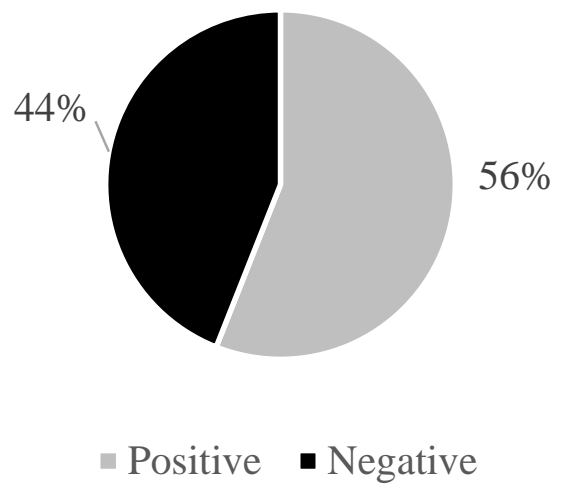

Figure 1: H. Pylori Diagnostic Test Results

56 percent of the sample tested positive for $\mathrm{H}$. pylori infection while 44 percent of the sample tested negative. (I.e. The infestation was below the level capable of causing symptoms)

Our results (demonstrated in Figure 2) show that the male population was tested positive for $\mathrm{H}$. pylori infection more often than female population. Hence more males experienced symptoms synonymous with peptic ulcer due to $\mathrm{H}$. pylori while more females experienced peptic ulcer like symptoms due to other probable causes.

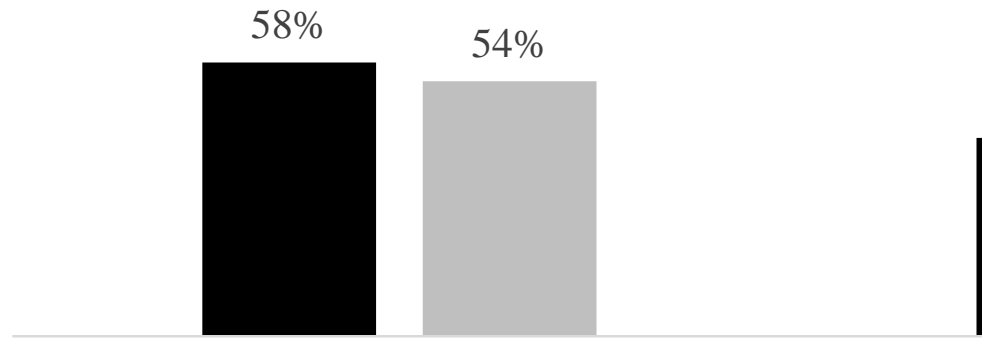

$54 \%$

Positive

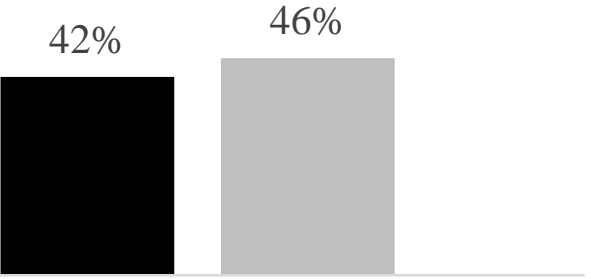

Negative

Males $\square$ Females

Figure 2: Gender Distribution

54 percent of the females tested positive for $\mathrm{H}$. pylori infection while 46 percent tested negative. On the other hand, 58 percent of the males tested positive for $\mathrm{H}$. pylori while only 42 percent tested negative. 


\begin{tabular}{lll}
\hline & Males & Females \\
\hline Mean & 8.6076 & 12.5346 \\
Median & 5.8650 & 10.2900 \\
Range & 24.09 & 56.28 \\
Minimum & 2.85 & 2.35 \\
Maximum & 27.57 & 58.63 \\
\hline
\end{tabular}

Table 1: Extent of H. Pylori Infestation in Our Sample (Micrograms/Deciliter).

The mean level of $\mathrm{H}$. pylori infestation in males was found to be lower than females. The large range put into question the validity of mean so we used another measure of central tendency "mode" which also turned out to be lower in males than in females. The minimum and maximum values of $\mathrm{H}$. pylori infestation ( $\mathrm{ug} / \mathrm{dl}$ ) reported in our sample, both, belonged to females.

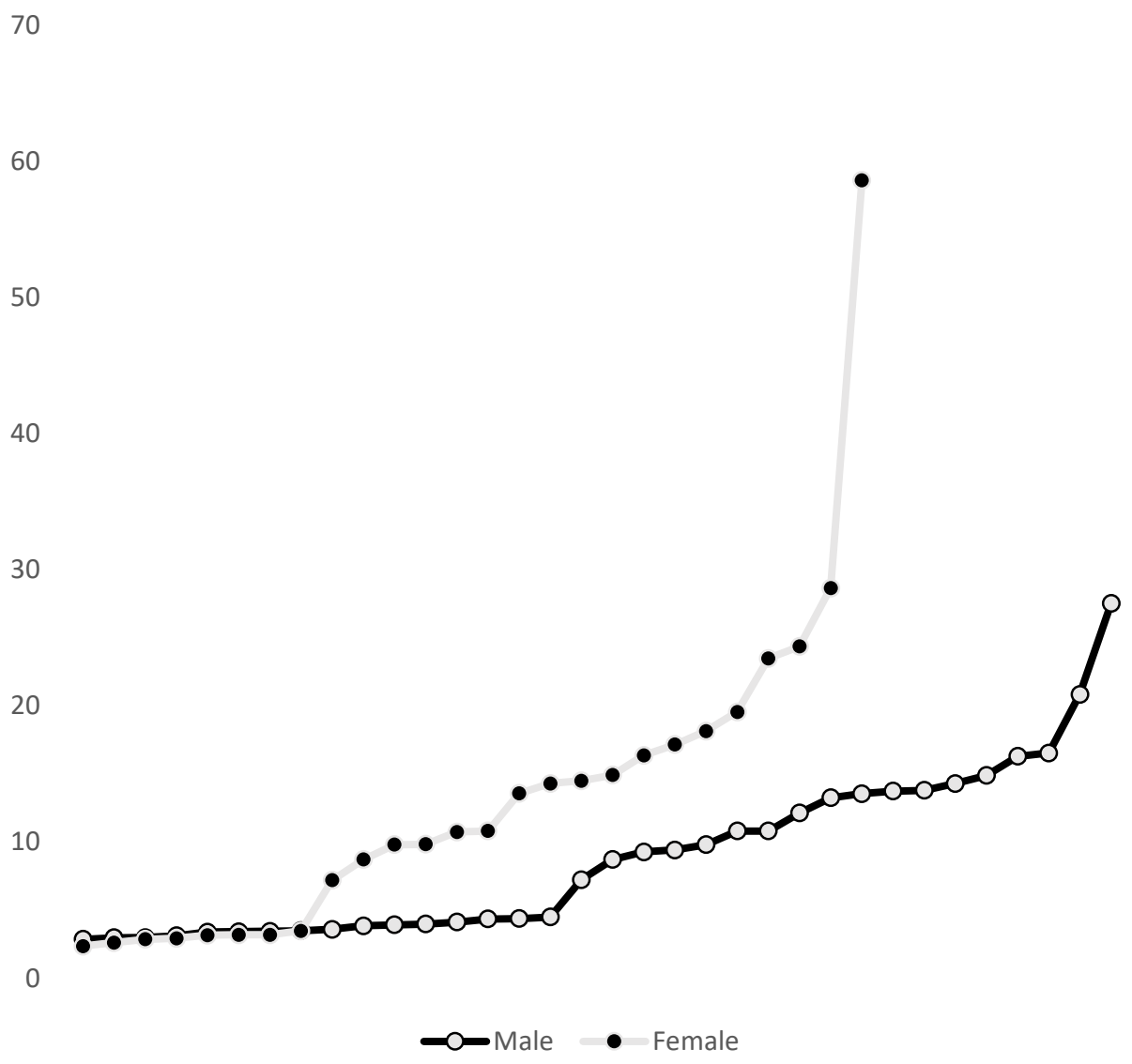

Figure 3: Comparison Between Male and Female H. Pylori Levels (Microgram/Deciliter).

It is clearly evident in Figure 3 that even though the incidence of $\mathrm{H}$. pylori is higher in males, the extent of infestation is more often severe in females. The line indicating amount of $\mathrm{H}$. pylori in female's peaks higher than that of the males while the line representing male's dips below the baseline level fewer times than females in first half of the graph. 


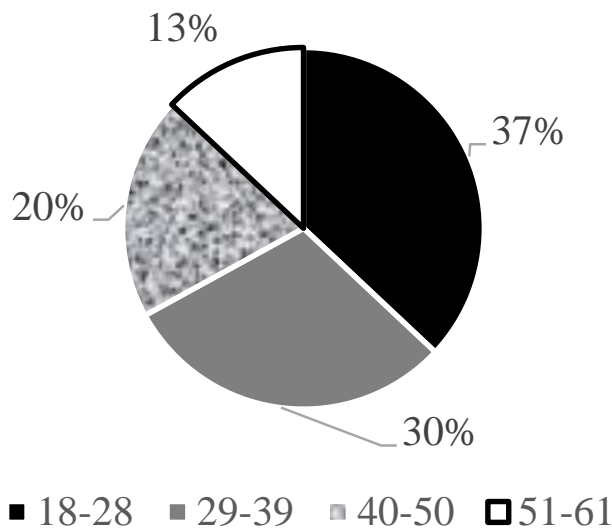

Figure 4: Chart of Incidence of Peptic Ulcer Symptoms in Different Age Brackets. Symptoms synonymous with $H$. Pylori infection was most common $(37 \%)$ in the and leading to the formation of ulcers $(\mathrm{Ma}$, 2011). age bracket from 18 to 28 years. The age bracket of 29 to 39 years immediately followed with $30 \%$ of the symptomatic patients. The general trend observed was that the incidence of symptoms was more in younger age group and decreased as the age progressed.

\section{Discussion}

Chronic helicobacter pylori infection is the prime causal factor for sixty\% and ninety\% of gastric and duodenal ulcers respectively (Hum Path, 2014). Owing to the fact that the bacterium resides in the antral mucosa, the immune system fails to clear it in spite of the appearance of antibodies. Since the uncleared infection persists for long, it acquires a chronic form of infection (gastritis in this case), leading to the failing of the mechanism that regulates production of gastrin by its normal anatomic site. Gastrin secretion can thus increase or decrease resultantly. Gastrin is responsible for the stimulating the parietal cells to produce gastric acid. In case of an ongoing helicobacter pylori colonization, the increased gastrin production leads to resultant hike in the acid production which thus is responsible for eroding the mucosa

It is interesting to note that during the past three decades, there has been a significant drop (due to the improved standards of living of the masses) in the incidence of duodenal ulcers, while a rise (probably owing to the hiked NSAID use) has been observed in the incidence of gastric ulcers (Johannessen, 2013). Apart from the hiked use of NSAIDS, excessive smoking is a culprit that is often held accountable for the hike in the incidence of gastric ulcers. Literature does rightfully correlate formation of ulcers with, (Kato, et al, 1992) however; an extensive literature further reveals that smoking alone might not be significant risk factors unless it occurs in tandem with infection of helicobacter pylori (Salih, et al, 2007; Martin, et al, 2008; Kurata, et al, 1997). In a similar manner, in-depth study reveals that many other agents formerly believed to be strong predisposing factors of ulcer production such as diet (spice and caffeine consumption) until the end of the twentieth century, are of relatively minor value (Kurata, et al, 1997; Ryan-Harshman, et al, 2004; Rubin, et al, 2001). Excessive use of alcohol like smoking does not seem to play a role worth consideration unless it 
occurs in tandem with helicobacter pylori infection.

The helicobacter pylori has affected around $50 \%$ of population worldwide each year, propelling the bacterium to the top of the list of infection causing agents in the world and the developing part of the world is troubled with a lot greater rate of infection than the developed world, where rates are calculated to be around twenty-five percent (Wang, et al, 2008).

The age at which one is intruded by the bacterium, plays an important part in disease progression and ultimate outcome. Patients that fall prey to the infection at a comparatively tender age are prone to suffer from heightened levels of inflammation that are usually seconded by atrophic gastritis and a greater consequent chance of developing gastric ulcer, gastric cancer or both. Infected individuals are observed to elicit other problems and more often than not, results in development of duodenal ulcer and not gastric ulcer (Brown; 2000). Infections are usually acquired in early childhood in all countries (Kusters, et al; 2006). The rates of acquiring the infection early in life are greater in the developing parts of the world, as compared to the developed parts. The reasons that may be behind this phenomenon may be the dismal state of sanitation and the low antibiotic usage rate in the developing world (NCBI; 2008). One might think that the condition is the same for children and elderly in the developed world and both experience a similar quality of life, so why does the rate of infection in the elderly not subside in the elderly too. The answer is that even though the conditions are good, there was a time that they were not as god as today and the elderly have experienced that poor episode of the past (Kusters, et al; 2006). The lesser incidence of infection in the developed world owing to the better standards of hygiene and common use of antibiotics would thus take time to reduce the infection levels independent of age in the future and for now we can rejoice in the fact the overall rates around the world are declining (Malaty; 2007).

\section{Conclusion}

On the basis of our result we conclude that $\mathrm{H}$. pylori was the leading cause of the gastro duodenal ulcers and inflammation symptoms in patients referred to the laboratory by doctors, both in males \& females at Shaheed Benazirabad. The incidence of $\mathrm{H}$. pylori induced symptoms was higher in males than in females while females seemed to be comparatively more affected by other probable causes (mentioned above). The $\mathrm{H}$. pylori levels were seemingly consistent in men but highly variable in women, this is evident from the fact that the highest \& lowest $\mathrm{H}$. pylori values both belonged to women. The younger age groups suffered more from symptoms while the elderly were less prone to face gastro duodenal ulcer \& inflammation symptoms. Further research needs to be done to confirm our findings at a larger scale.

\section{Conflict of Interest}

N/A

Acknowledgment

N/A

\section{References}

- Antral Mucosa. (November 11, 2005). Human Pathology.

- Helicobacter pylori J99. (September 1, 2008). Genome Browser Gateway.

- Sonnenberg, A., Müller-Lissner, S. A., Vogel, E., Schmid, P., Gonvers, J. J., Peter, P., Strohmeyer, G., Blum, A. L. (1981). Predictors 
of duodenal ulcer healing and relapse. Journal of Gastroenterology 81(6), 1061-1067.

- Brown, L. M. (2000). Helicobacter pylori: epidemiology and routes of transmission. Epidemiol Rev, 22(2), 283-297.

- Butcher, G. P. (2003). Gastroenterology: An Illustrated Colour Text. Elsevier Health Sciences. 24-25.

- Bytzer, P., Dahlerup, J. F., Eriksen, J. R., Jarbøl, D. E., Rosenstock, S., Wildt, S. (2011) Diagnosis and treatment of Helicobacter pylori infection. Danish Medical Bulletin. ;58:C4271.

- Fuccio, L., Zagari, R. M., Eusebi, L. H., Laterza, L. Cennamo, V., Ceroni, L., Grilli, D., Bazzoli, F. (2009). Meta-analysis: can Helicobacter pylori eradication treatment reduce the risk for gastric cancer. Ann Intern Med, 151(2), 121-8.

- Johannessen, T. (1995). Management of peptic ulcer disease in general practice. Scandinavian journal of primary health care, 13(4), 241-242.

- Ikuko, K,. Abraham, M. Y., Nomura, Grant, N., Stemmermann, Chyou, P. H. (1992). A Prospective Study of Gastric and Duodenal Ulcer and Its Relation to Smoking, Alcohol, and Diet. American Journal of Epidemiology, 135(5), 521-530.

- Kurata, John, H., Nogawa, Aki, N. (1997). Meta-analysis of Risk Factors for Peptic Ulcer: Nonsteroidal Anti-inflammatory Drugs, Helicobacter pylori, and Smoking. Journal of Clinical Gastroenterology, 24(1), 2-17.

- Kusters, J. G., Van-Vliet, A. H., Kuipers, E. J. (2006). Pathogenesis of Helicobacter pylori Infection. Clin Microbiol Rev, 19(3), 449-90.

- Ma, L. S. (2011). Tribute to Dr Frank I Tovey on his 90th Birthday. World Journal of Gastroentrology, 17(31), 3565-3566.
- Malaty, H. M. Epidemiology of Helicobacter pylori infection. (2007). Best Pract Res Clin Gastroenterol 21(2), 205-214.

- Martin, David, F., Montgomery, E., Arthus, S., Dobek, Geoffrey, A., Patrissi, M. A., David, A., Peura, M. C. (2008). Campylobacter pylori, NSAIDS, and Smoking: Risk Factors for Peptic Ulcer Disease. American Journal of Gastroenterology, 84(10), 1268-1272.

- Rubin, R., David, S., Strayer, Rubin, E., Aponte, G. (2001). Rubin's pathology: Clinicopathologic foundations of medicine (Sixth Edition). Philadelphia: Wolters Kluwer Health/Lippincott Williams \& Wilkins.p. 623.

- Ryan, Kenneth. (2010). Sherris Medical Microbiology. McGraw-Hill. pp. 573, 576.

- Ryan-Harshman, M., Aldoori, W. (2004). How diet and lifestyle affect duodenal ulcers. Review of the evidence. Canadian family physician Medecin de famillecanadien. 50, 727-732.

- Salih, Barik, M,. Abasiyanik, F., Bayyurt, N., Sander, E. (2007). H pylori infection and other risk factors associated with peptic ulcers in Turkish patients: A retrospective study. World Journal of Gastroenterology, 13(23), 32453248. PMID 17589905.

- Suerbaum, S., Michetti, P. (2002). Helicobacter pylori infection. N. Engl. J. Med, 347(15), 1175-1186.

- Wang, G., Maier, R. J. (2008). Critical role of RecN in recombinational DNA repair and survival of Helicobacter pylori. Infect. Immun, 76(1) 153-160.

-Wu, Q., Yang, Z. P., Xu, P., Gao, L. C., Fan, D. M. (2013). Association between Helicobacter pylori infection and the risk of colorectal neoplasia: a systematic review and meta-analysis. Colorectal Disease, 15(7), 352364. 